\title{
Public Speaking and Online Peer Feedback in a Blended Learning EFL Course Environment: Students' Perceptions
}

\author{
Latifa El Mortaji ${ }^{1}$ \\ ${ }^{1}$ School of Humanities and Social Sciences, Al Akhawayn University in Ifrane, Ifrane 53000, Morocco \\ Correspondence: Latifa El Mortaji, School of Humanities and Social Sciences, Al Akhawayn University in \\ Ifrane, Ifrane 53000, Morocco.
}

Received: November 1, 2020

Accepted: January 26, 2022

Online Published: January 27, 2022

doi: 10.5539/elt.v15n2p31

URL: https://doi.org/10.5539/elt.v15n2p31

\begin{abstract}
This paper reports on a blended learning approach for public speaking in an English as a foreign language (EFL) context. The researcher implemented the course design through reduced weekly face-to-face class sessions and online student interaction using a speech video-based blog. Using a survey conducted at the end of the semester, multiple comments provided for online peer feedback, structured outlines submitted to Turnitin, and instructor's weekly observation of the students' presence and performance online, the researcher collected data about the students' progressive learning of the public speaking skills, peer feedback, and the students' assessment of each aspect pertaining to the blended learning experience. The qualitative analysis revealed the effectiveness of online peer feedback in public speaking skills development as demonstrated by students' attainment of course intended learning outcomes, as well as an overall positive student perception towards the blended learning model, with minor reservation of less confident students at the onset of the online implementation phase.
\end{abstract}

Keywords: blended learning, public speaking skills, face-to-face and online, feedback, speech-video blog, LMS, Turnitin.com, COVID-19

\section{Introduction}

\subsection{Definitions}

Teachers, professors, and specialists in the field altogether have contributed to the innovation of new mechanisms, thus taking an extra step towards finding better, efficient, and effective ways on the journey of student building. Blended learning is one of these innovations. With origins dating back to the 1840's (Pappas, 2019), the term Blended Learning (BL) can hint at a mix or a blending of two things. Oliver and Trigwell adjudged in a critical analysis in 2005 that blended learning naturally demands the use of a minimum of two different approaches for a given subject (Hrastinski, 2019). A good example to further elaborate on this point would be Sir Isaac Pitman's launching of a "distance education course" (Pappas, 2019) back in the 1840's in what might be considered as the first blended learning course. In addition to a classical face-to-face class, Sir Isaac started mailing short texts to his students who were required to send them back in order to be corrected and graded (Pappas, 2019). It wasn't until the 1960's that a very initial interpretation of blended learning using computers appeared (Bersin, 2004). Training had gradually switched from being instructor-led to being automated; PLATO (Programmed Logic for Automatic Teaching Operations) was a program that had a set of courses offered from multiple academic levels (Bersin, 2004).

Blended Learning also referred to as "Web-enhanced instruction", "hybrid learning" and "technology mediated instruction" (Martyn, 2003) is in its core, as Graham stated in 2013, a combination of physical, teacher to student, face-to-face instructions and network mediated, online classes. It was also called the "new traditional model" (Ross and Gage, 2006) and was considered as the modern way of teaching and Norberg et al. in 2011 referred to it as "the new normal" (cited in Dziuban, Graham, Moskal, Norberg, \& Sicilia, 2018). Historically, the term was prone to multiple interpretations, making the process of pin-pointing a single unique definition of the concept quite challenging. If we look at it from a notoriety point of view, one can argue that the true definition of the term would be one of the two most cited definitions in related literature (Hrastinski, 2019), including the definition of Graham (2006) which is that "blended learning systems combine face-to-face instruction with computer-mediated instruction" (Hrastinski, 2019), and the definition of Garssion and Kanuka (2004) whereby 
they explain that hybrid learning is the astute assimilation of a face-to-face classroom experience with a digitalized learning experience (cited in Hrastinski, 2019).

BL is then "a term that lacks a unified definition" (2018); and finding a single definition to this teaching method has been a historic process: One definition given to the teaching method was described as the support of all assets of electronic learning, notably the reduction of costs, time adaptability, and location comfort and access for the student body (Brown, 2003, as cited in Akkoyunlu \& Soylu, 2008). In previous research in 2001, Singh \& Reed stated that blended learning is but a mechanism where more than a single method of delivery is used to improve both the cost and outcome of the learning (Akkoyunlu \& Soylu, 2008). In 2012, Friesen (as cited in Rao, 2019) stated that it is the scope of opportunities offered in the event of working with the duality of utilizing the internet and related media and a classroom that demands the physical existence of both the learners and the professor. Based on the slight changes of the researched definitions throughout the last decade, it is apparent that the combination of face-to-face learning and mediated instruction is imperative. Therefore, we can conclude that Blended Learning can be defined as a process that explores educational methods by enforcing a strategic "blending" of a classical learning approach in a classroom, an on-site traditional teaching method, with mobile schooling and computer-mediated tasks, while having the benefits of two methods at the best interest of the parties involved.

The use of computer mediated tasks is not to be taken for granted. Indeed, computers can be daunting for many learners and may have the opposite effect on the expected learning outcome. To formally frame the parameters involved in making use of computers, Davis put forward a theoretical model called Technology Acceptance Model (TAM) (Davis, 1989; Davis, Bagozzi, \& Warshaw, 1989). TAM factors in four key parameters, namely four key constructs of the TAM were assessed: perceived ease of use (PEU), perceived usefulness (PU), subjective norm (SN), and behavioral intention to use (BIU). Since then, many researchers evaluated the use and assimilation of computer based tools and methods in various learning settings by measuring the four key parameters, taking into account gender, subject, and other variables, the latest of which is the study by Walker et al., and Vallade et al. on practicum-based classes such as Public Speaking, which we are concerned with in this study (Walker et al., 2019; Vallade et al., 2021).

\subsection{Blended Learning Models}

The variety in the definition proposed for "Blended Learning" did not stop at explaining what the term means, but even influenced the different models it has: Just as there are multiple definitions, multiple models were suggested. Garrison and Vaughan (2008) developed a model for blended learning called the community of inquiry framework. This community of inquiry can be explained as a community where the core of higher education is carved by a clear, goal-set and disciplined lecture (Hrastinski, 2019). This model is constructed upon three pillars of presence: "Cognitive presence", "teaching presence" and "social presence" (Hrastinski, 2019). This model, community of inquiry framework, is perceived as a paradigm when it comes to secondary education experience. Although it was not built specifically for blended learning, it can be applied in it just as well as it can be applied in Brick and Mortar or Online classes (Garisson and Vaughan, 2008).

Meanwhile, blended learning was perceived in its essence, a continuum between physical classes and computer-mediated ones by Watson (2008). This continuum was set and divided between seven categories that make up a balance of the two portions included in the hybrid learning program: It ranged from category 1 where learning is fully online with no physical classes held, followed by category 2 where learning was fully computer-based with options offered for a face-to-face teaching. The following categories gradually moved up in the same fashion, where the online component is decreasing as the classic classroom portion of the class increases, until the last category: Brick and mortar classes with little to no computer mediatized resources (Hrastinski, 2019).

In 2012, Staker and Horn deeply analyzed the possible model of blended learning along the K-12 levels, which lead them to conferring four entirely different models of teaching method (Hrastinski, 2019). The first one is the rotation model, a model where the studied course is "rotated" on a schedule set by the teacher or the professor in addition to other modalities that the class might take part of (Staker \& Horn, 2012). This model can be further sub-categorized into four models of its own: 1. "Station rotation", referring to when a course that is being taught in a classroom or a group classroom has multiple modalities and activities, which are referred to as stations, and the students rotate between these stations (Staker \& Horn, 2012). 2. "Lab Rotation", and it refers to a class where students rotate to a space for the computer-based portion of the class, usually a computer lab (Staker \& Horn, 2012). 3. "Flipped Classroom", when students take part in the online portion of the class in a site dedicated for homework-like activities, then they go to the traditional, teacher-to-student class space (Staker \& Horn, 2012). 4. 
"Individual Rotation": it can be described as a class where every single student has his own personalized and individual station and playlist of work, set up and managed by the teacher. The second model that Staker \& Horn presented is the flex model; it refers to where the class content is given to students initially online, and then the class follows up with individually given face-to-face session to students as needed by the student body. The third model is the self-blend model; it is basically enrolling in at least one more course to add to traditional classes (Staker \& Horn, 2012). Finally, the fourth model is the enticed-virtual model where the student body manage their time between going to a physical face-to-face class and attending a computer-based class.

The true benefits of these models can be further shown if put into a context. In this study, the BL model was implemented in an originally traditional public speaking course, and prior research conducted in this context has revealed many benefits with a list of difficulties encountered in the process of implementing a blended learning public speaking context.

Furthermore, today, with the realities of COVID-19 pandemic repeated waves that restrict access to class, this model of BL for teaching public speaking course can be a very effective way in attaining learning objectives, while coping with imposed face-to-face intermittence.

\section{Literature Review}

Public speaking can be simply defined as an uninterrupted form of formal speech from a speaker to an audience (Ibrahim \& Yusoff, 2013), and according to the literature, it can "significantly" benefit from online teaching methods, such as the blended learning mode (Ainol and Zailin, 2012). Ibrahim \& Yusoff (2013) conducted a study in an English as a foreign language learning context whereby the ILOs of the class roamed around focusing learners onto the speechmaking action of 40 undergraduate engineering students. The students were exposed to two forms of speech: persuasive and informative. The researchers explained that the process of the blending involved course lectures held in face-to-face classes twice a week, with a combination of sample speeches and other multimedia aid that were shown to the learners. The course focused on using "Wikispace" as their online platform for the blended learning process. "Wikispace" is a google site platform that is used by teachers as well as many other personnel to manage some form of content to be shared with a community. The course had videos to help students with the language learning and pronunciation as well as sample speeches for further help on their assignments (Ibrahim \& Yusoff, 2013). After two weeks of using the BL mode, the learners were asked to fill out a questionnaire to get data about what students were using the platform for most. Results revealed that over $90 \%$ were using the platform for speech practices, recording, drafting speeches and visiting the lectures recordings, with $82.5 \%$ giving feedback to their classmates about their work (Ibrahim \& Yusoff, 2013). By the end of class, only about $20 \%$ still felt a little nervous to have an audience to give their speech to, while about $42.7 \%$ said it was a great experience, with $27.5 \%$ of them stating that they loved the fact that they could share their recorded speeches with an audience. At the end of the course, about $57.5 \%$ of enrolled students reported preferring the hybrid learning approach over the traditional one (Ibrahim \& Yusoff, 2013).

In another study, 44 senior English students who were enrolled in an English Public Speaking class were asked to record themselves while giving out speeches as an assignment (Shih, 2010). They enjoyed the freedom of choosing their topic, as long as they were persuasive or informative. The students were allowed to repeat the drafting and recording process as many times as they needed before a set deadline (Shih, 2010). The implementation of this course followed a 4-phase process, where the class started in a face-to-face basis in phase 1 , then decreased to only a third of the class in phase 2 leaving $75 \%$ of class content to be done on an online platform, then diving the two ends by half in phase 3 , to get back to a traditional face-to-face class in the $4^{\text {th }}$ phase of the course (Shih, 2010). Meanwhile, the class used a combination of student blogs in their mother tongue, Chinese, and shared video media in the learning language, English. In addition, the course implemented a "Blog Learning Satisfaction Survey (BLSS)" in Chinese. These questions had a goal of getting more data about the students' perceptions about the hybrid learning course. It was stated that the online interaction helped $82 \%$ of enrolled students in terms of improving their "professional communication skills", with a focus on "pronunciation" and "mannerism" (Shih, 2010). The students expressed how their ability to correct their own mistakes and improve self-learning was increased through peer review. It was also concluded that the usage of an online platform helped with the learning process of knowing how to manage a multimedia software (Shih, 2010). The researcher recommended more studies on public speaking using a blended learning model.

These two studies provide confirmation regarding the usage and assessment of a blended learning model within a higher education academic context. However, there are still issues and imperative preparations to be considered; a blended class layout is crucial to the actual running of the class, on all aspects. Both parties must be familiar with the usage of the online platform or have had some form of training (Shih, 2010). Some learners have also 
suggested that for the goal of the entire student body taking the remote learning part in a more serious manner, a certain percentage should be allocated to the online portion instead of having it as an informative platform (Ibrahim \& Yusoff, 2013).

Kintu and Zhu (2017) investigated the relationship between "student characteristics" and "design features of blended learning" and learning outcomes in a blended learning environment. Using a sample of 238 Ugandan students across different schools, they evaluated the effectiveness of the blended learning design. They collected data using Barnard's (2009) online self-regulated learning questionnaire (OSLQ) and the Intrinsic Motivation Inventory (IMI) by Deci and Ryan (1982). Results showed that student attitudes towards blended learning and a good command of technology use are important factors and "crucial too for satisfaction and motivation as well as learner knowledge construction" (7.1.).

Yeh et al. (2016) conducted a study on the effects of online peer feedback on EFL students' speaking performance. Three sources of data collection were used: recorded videos, blog entries, and students' self-reflections. The researchers used students' grades they had received in the first and final video clips to divide them into two groups of high and low progress achievers. It was found that students who received peer feedback demonstrated significant progress in their video clips in terms of "content development", while both groups showed significant progress in the delivery" (1). The authors concluded that the students who had more online interactions "gained more progress in the revised clips".

Suzan Qindah (2019) conducted a study to investigate the impact of blended learning on Palestinian students' usage of grammar in an EFL context. The researcher collected data using pre-post tests and interviews. Quantitative and qualitative data analysis revealed that "blended learning has positive effect on students' achievement in grammar instruction", based on the learning achievements of the 'experimental group' that outperformed the 'control group'. The interviews showed students' positive attitudes towards the teaching material that was used in the blended learning environment; they found it 'enjoyable and beneficial' for it enabled them to retain information, to get immediate feedback after quizzes, and to improve English pronunciation and listening skills. As for the limitations of the blended learning environment, the students reported that they did not access the online material from home due to lack of internet or simply the heavy workload, and some said they could not understand all the material without the presence of their teacher.

The literature review revealed that (i) blended learning is an effective learning model; (ii) one should be aware of its advantages and disadvantages based on learning outcomes, technology, applications and so on; and (iii) more studies on public speaking using a blended learning mode were recommended. This research intends to bridge this gap and to provide more insight on the subject matter. To do this, and unlike the studies mentioned, the researcher developed a blended learning public speaking course using a known environment to the students. The latter were familiar with the web-based applications used, such as the LMS (Jenzabar) and Turnitin, since their home institution has been using these systems as official platforms for many years, and students were used to uploading their assignments and accessing instructor's teaching material. In addition to their own devices, students were using computer labs on campus, which was expected to facilitate their learning. Furthermore, with the technology and technical support available on campus, the researcher was not worried about connection issues and access to course material on LMS, or any other limitation as reported in most studies above. There was a concern though with recording and uploading speech videos on the blog and students' effective presence online to provide peer feedback, and the researcher took care of progressively introducing the students to the online platforms and environment as explained in the research methodology.

\section{Methodology}

\subsection{Research Questions}

This study aims to answer the following questions:

RQ1. Is the students' online presence and performance effective?

RQ2. How do students perceive blended learning as a teaching mode in their public speaking course?

\subsection{Participants}

Forty-eight (48) university students were enrolled in a Public Speaking course in spring semester across three different sections. Twenty-seven (27) students were in their second semester and twenty-one (21) students were in their third semester of study. The students aged 18 to 19 came from different academic backgrounds, including Business Administration, Engineering, and Humanities and Social Sciences, and they took the course as part of a common core. They had no prior public speaking experience, except for a few who had limited exposure to audiences in high school through presentations and debates. The participants represented a 
homogeneous group because they were exposed to academic English instruction for approximately the same number of years. In addition, all participants were multilingual and had access to four languages, including Arabic, French and English.

Out of the 48 students who participated in this study, there were 26 females and 22 males. The complete demographic data are tabulated in Table 1.

Table 1. Students' demographic and academic background

\begin{tabular}{lllllll}
\hline & Number & $\%$ & Age group & Business Major & $\begin{array}{l}\text { Engineering } \\
\text { Major }\end{array}$ & $\begin{array}{l}\text { Humanities and Social } \\
\text { Sciences Major }\end{array}$ \\
\hline Males & 22 & $46 \%$ & $18-19$ & 12 & 8 & 2 \\
Females & 26 & $54 \%$ & $18-19$ & 12 & 11 & 3 \\
Total & 48 & $100 \%$ & $18-19$ & 24 & 19 & 5 \\
\hline
\end{tabular}

The participants signed a consent form prior to the study to allow the research to publish named samples of their outline submissions on Turnitin and their peer feedback on the course blog for research purposes. As for the speech videos, the course blog had already been published publicly at the onset of class with the agreement of all the speakers to be used as a teaching tool to watch classmates' speeches and post constructive feedback for the study.

\subsection{Procedure}

The public speaking course was initially offered twice a week on Tuesdays and Thursdays. Each class session took one hour and twenty minutes. In addition to the face-to-face class meets, the students were required to meet each other online. Prior to the online interaction, the students had received formal instruction in class, including speech analysis activities (see figure 1). Then, the professor created a course blog whereby students uploaded formal video-recorded speeches in four genres: self-introduction, informative, persuasive, and special occasion. The students were required to meet online quite regularly to watch their own performance and that of their peers, then post peer feedback using the knowledge and new concepts acquired in class about speech preparation and delivery skills. The professor checked the students' online participation on a weekly basis, watched the videos, read all posted comments, and took note of her observation. Progressively, the students had more online interaction, and the class meets were reduced to one session a week for one hour and twenty minutes.

\subsection{Data Collection}

The researcher collected qualitative data through a survey, a video-based blog, and observation. The researcher observed the students' online presence and performance through speeches and student feedback posted on the video-based course blog, to collect data on the students' commitment and their online independent learning. Upon completion of the course, in week 14, the researcher administered a student survey consisting of three main questions pertaining to the students' perceptions of the face-to-face classroom instruction, the online student interaction, and the overall blended learning environment. All forty-eight students completed the survey.

Although no statistical tools were used to ensure the Reliability and Validity of the instruments used in this research, namely Questionnaire, and students' feedback on the Blog, their design inherently catered for many of the criteria suggested by Morse (Morse, 2002) for the rigor of Qualitative research Instruments. Specifically, the questions were simple and direct, and were reviewed by a colleague faculty for ease of understanding, ambiguity, bias, and leading questions. The very structure of the Blog -posting of comments- also satisfies the reliability and validity criteria. Finally, the data were collected electronically to avoid any misses or errors in students' answers.

\section{Course Design Implementation}

The instructor designed a blended learning environment that required weekly traditional face-to-face interaction in the classroom and online students' interaction through the course blog. A list of activities involved in both the face-to-face and online settings is presented in Figure 1. 


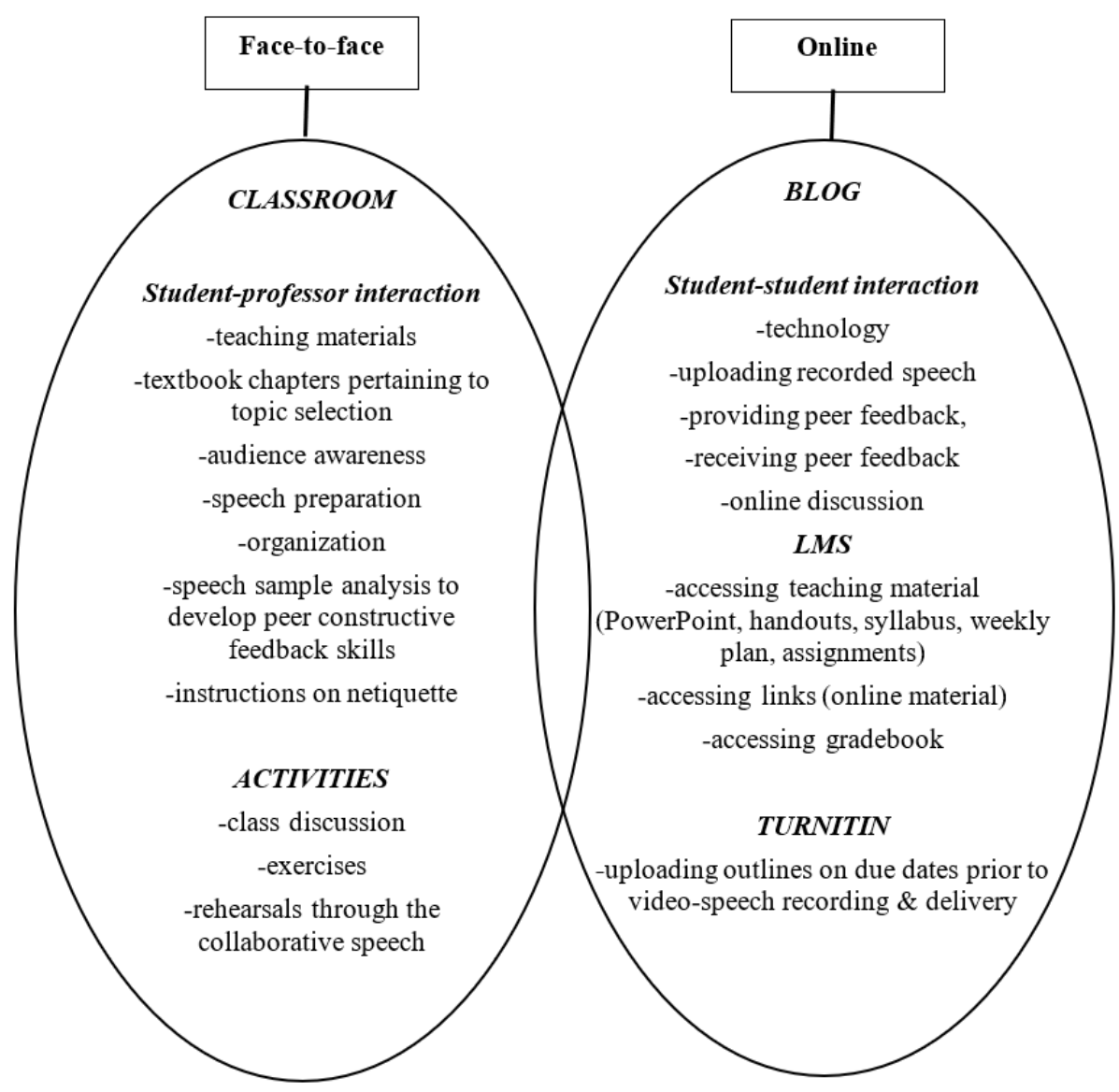

Figure 1. Public speaking blended learning model

\subsection{Face-to-Face Class Instruction}

\subsubsection{Teaching Material}

The face-to-face weekly class meets enabled the students to get all the needed course material, including lectures, sample speech analysis, and class discussions. Using The Art of Public Speaking textbook (2012), the instructor covered eighteen main chapters in the classroom through the students' "chapter presentation activity" that was followed with a class discussion to introduce the students to the main teaching material, including: (i) the context of public speaking (e.g. historical background, the speech communication process, and ethics in public speaking); (ii) types of formal speeches, the main organizational patterns, and the speech outline; and (iii) audience consideration (e.g. interaction, diversity), delivery (verbal and non-verbal communication), use of note cards, gathering supporting materials, using visual aids, language. To put all the studied theory into practice, the instructor used tens of You Tube speech samples that come originally with the textbook. Through speech analysis activities in the classroom, the professor guided the students in learning the concept of peer feedback and how to provide peer constructive feedback highlighting strengths and areas for improvement, with a view to helping their peers improve from one speech to another.

\subsubsection{Rehearsals Through the Collaborative Speech}

The face-to-face- sessions took place in the classroom where the instructor organized class discussion of teaching material, exercises, and speech samples' analysis. A few extra face-to-face sessions were scheduled in an auditorium whereby the instructor guided the students' performance through collaborative impromptu speaking. Using a large stage, the students performed together in small groups and delivered the "collaborative impromptu speech" (El Mortaji, 2018). This activity served the purpose of creating classroom connectedness, tackling stage fright and anxiety issues, and improving delivery skills (El Mortaji, 2017); it enabled the students to put theory into practice and get ready for the self-recorded graded speech. Prior to the blended learning environment, the researcher scheduled three impromptu speaking sessions in the University Auditorium to introduce the students to relaxation exercises and collaborative activities for "anxiety reduction" (Rumbough, 1999; El Mortaji, 2017) and "classroom connectedness (audience)" (El Mortaji, 2018). 


\subsubsection{Instruction on Netiquette}

Prior to posting online peer feedback on the course blog, the students practiced netiquette in the classroom. The instructor introduced them to the concept, which is a combination of 'net' and 'etiquette' and provided them with a list of rules and guidelines about what to do and what not to do online. They were required to observe netiquette using nice manners, mutual respect, and decent language. They were reminded to always review their comments and to avoid abusive messages when highlighting weaknesses of the speaker/speech. In addition, the students were instructed to be accurate and to proofread messages for spelling and punctuation mistakes before posting online, and to use simple clear English with no emojis. Finally, the students were instructed to always have their names clearly printed next to their comments in case the speakers needed to discuss further the provided peer feedback. Anonymous comments were not welcome and strictly discouraged.

\subsection{Online Interaction}

\subsubsection{The Video-Based Course Blog}

The professor created a course blog whereby the students were required to upload their recorded speeches. Given that the speeches had different rhetorical genres, they differed in terms of requirements (content and organizational patterns), timing, and use or non-use of visuals. The forty-eight students were required to meet online every week and watch their performance and that of other students across different sections to provide online peer feedback. The students were instructed to avoid double submission and watch complete videos before providing feedback. Figure 2 is a sample of the students' uploaded recorded speeches on the public speaking course blog.
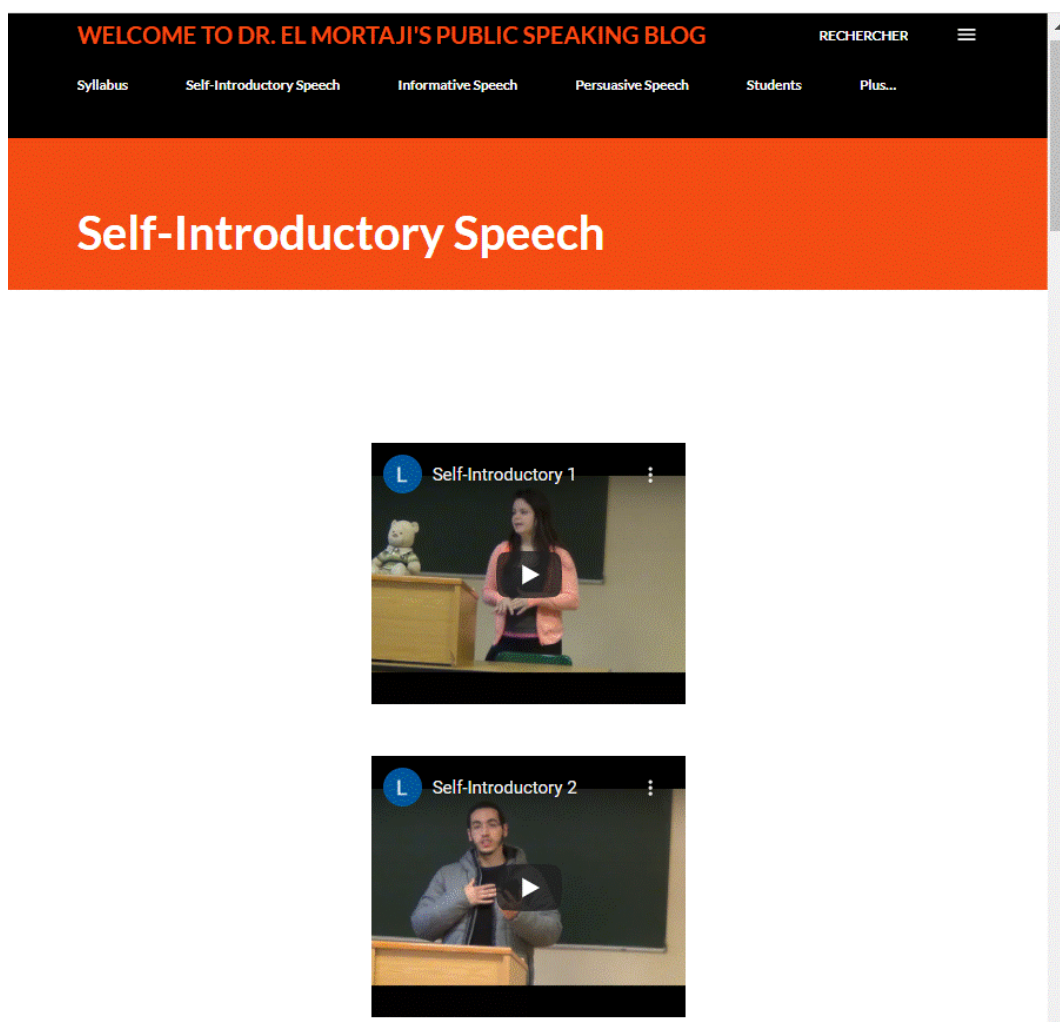

Figure 2. Sample of students' introduction speech videos posted on the course blog

As observed in Figure 2, the students' informative speech was video recorded in the classroom. Using the school's professional camera, the professor demonstrated to the students how to video record their speeches and upload them in the course blog themselves for online interaction and peer feedback. To keep the notion of the 'audience' in public speaking, the students met in groups to help record each other's performance and serve as audience, and then upload the speeches in the course blog. Thanks to the instructor's guidance, demonstration and reminders that took place in the classroom in Weeks 2 and 3, the students did not encounter any technical problems in the recording and uploading process. 

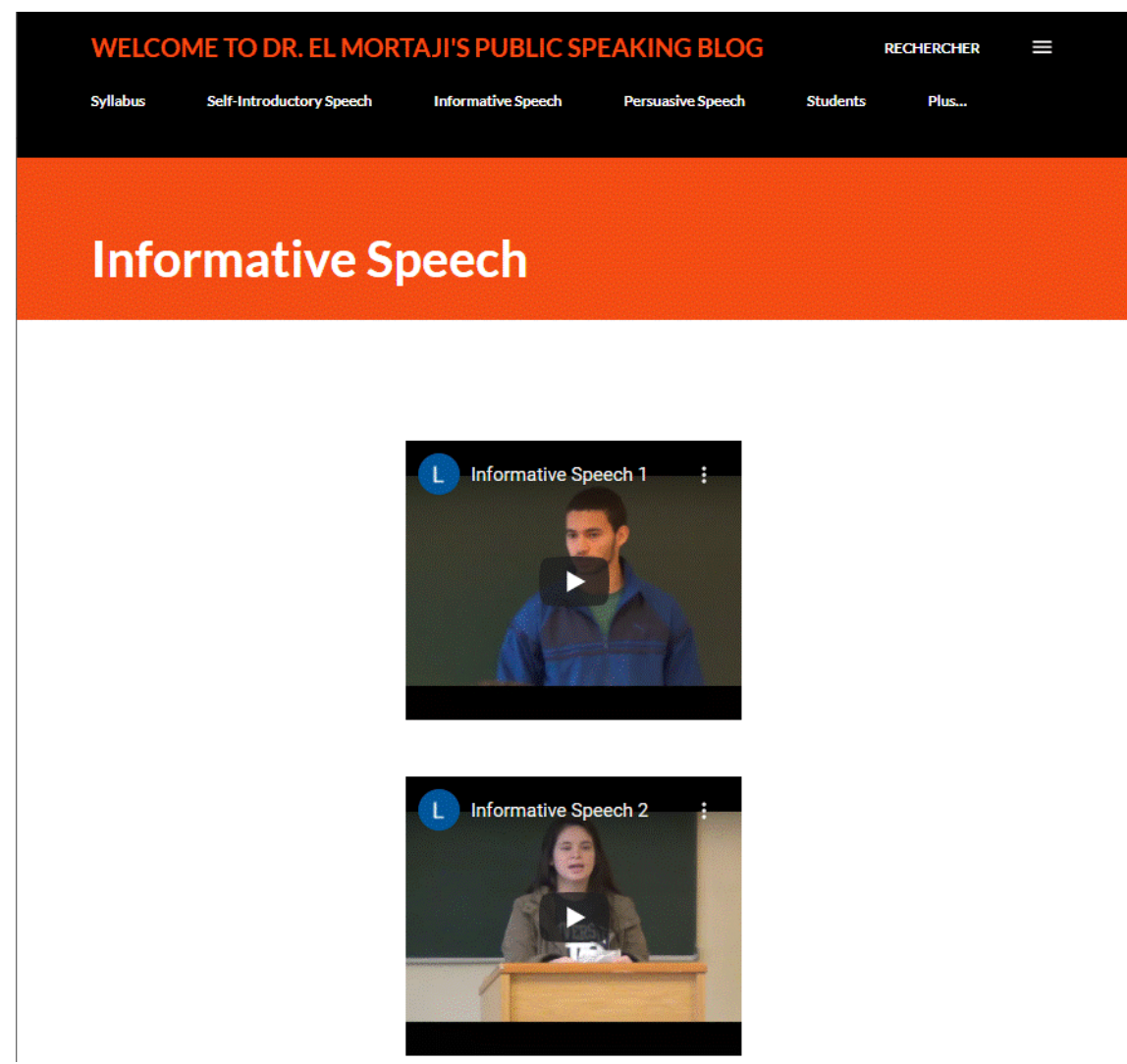

Figure 3. Sample of students' informative speech videos posted on the course blog

\subsubsection{Learning Management System (LMS)}

The instructor used the institution's official platform Learning Management System (LMS) to post the course syllabus, the textbook, handouts, the speech assignments, and links for samples of speeches. Students were provided with their ID to access the course content online. LMS also displays individual and overall grades so that students can keep track of their progress in the course. Since video speeches could not possibly be uploaded on Jenzabar, the portal, due to their size, the instructor created a common course blog for all forty-eight students to post their videos and provide peer feedback.

\subsubsection{Turnitin.com}

Prior to their speech delivery, students submitted two-to- three page long structured outlines for each of the academic speeches to the institution's plagiarism prevention service www.turnitin.com. The platform provided the instructor with the tools that enabled students to engage in the writing process of their speech outline and submit multi-drafts. Resubmission by overwrite was enabled by the instructor and students received their personalized feedback and originality reports. The instructor provided the students with the enrollment key and the password to enable the students to assume the responsibility of submitting their outline on the due date, and failure to do that resulted in a zero.

\section{Data Analysis and Results}

This section reports on the students' online presence and performance in terms of uploading their recorded speeches (see 4.2.1), providing and receiving feedback, and the students' achievements of course intended learning outcomes together with their perceived impact of the Blended Learning mode on their public speaking skill development over the course of the semester.

Prior to online interaction, the researcher scheduled three impromptu speaking sessions in the University auditorium to introduce the students to relaxation exercises and collaborative activities for anxiety reduction (Rumbough, 1999; El Mortaji, 2017) and classroom connectedness (El Mortaji, 2018). In addition, the instructor introduced the students to important concepts like peer feedback and samples of speech analysis activities to prepare the students for their independent online interaction and learning. 


\subsection{Online Peer Feedback}

RQ1: Is the students' online presence and performance effective?

The forty-eight participants posted a total number of 188 comments on the blog to assess their peers' four speeches. These comments were mostly written in three to nine complete sentences, and sometimes in the form of long paragraphs. The peer feedback covered different aspects of the speakers' performance pertaining to speech preparation and speech delivery. Samples of students' online feedback are presented in Table 2.

Table 2. Types of peer feedback and samples of students' comments

\begin{tabular}{ll}
\hline Types of Comments & Samples of Peers' Comments \\
\hline CONTENT & \\
- topic & - The speaker clearly introduced his topic in the introduction. \\
- main points & - I like the attention grabber. \\
- central idea & - The speech had a good content. \\
- transitions & - The main points were implicitly mentioned in the central idea. \\
- sources & - In the body the main points were clear, supported, and logically presented. \\
- quote & - The transitions between the main points were also clear and effective. \\
- attention grabber & - The most important thing that was respected in the three speeches is the selection of \\
- establishing credibility & organizational pattern and following it perfectly. \\
- organization & - The speaker established her credibility through extensive research. \\
& - The most important thing that was respected in the three speeches is the selection of \\
& organizational pattern and following it perfectly. \\
& - He clearly referred to the three main sources he used.
\end{tabular}

\section{NON-VERBAL COMMUNICATION}

- eye contact / movement

- posture

- facial expressions

- gestures

- body language

- The speaker maintained good eye contact with the audience.

- Going through her note cards did have an impact on her eye contact. So, it was about $75 \%$ maintained with the audience.

- The speaker's facial expressions were too tense. He looked very serious, while actually the topic is about a happy occasion speech.

- The student used a lot of mannerism. She touched her hair many times. May be next time she can use a hair bang.

- The posture of the speaker was not good because he was moving back and forth, probably because he was nervous. But a few seconds later he maintained a better posture. Well done!

\section{VERBAL COMMUNICATION}

- voice

- tone

- speech rate

- breathing

- language

- enunciation

- accent
- The speaker in the second video talks using a conversational style and a fluid language. It helped the speaker to breathe and speak naturally.

- The speakers use a lot of techniques we learned at class such as using a high voice, intonation. Good job!

- The speaker has improved from speech 1 to speech 2 because his tone was monotonous and now in this speech. I can hear ups and downs, good intonation.

- The speaker speaks so fast in the conclusion.

- The speaker has a nice accent she is a native speaker.

- I very much liked the speaker's articulation of every word. I could hear the word endings. 


\section{USE OF VISUALS}

- selection

- presentation

- standing point

- consistency

\section{ALLOTTED TIME \\ - within allotted time \\ - beyond allotted time}

- I enjoyed listening to the first speech since the speaker presented the main points clearly and used visuals to support his arguments.

- The speaker was very good in selecting appropriate visuals like statistics and pictures that helped better explain ideas to the audience.

- The speaker used the technique of leaving one blank slide between each visual. Its' obvious he practiced the technique the professor emphasized in class. Also, her standing point was perfect. Excellent!

- The speaker was talking at different pace. While the beginning was nice, clear, and slow, the end of the speech was rushed probably because he was using more than 5 minutes and he shouldn't.

- The speaker used so little time; she did not share much in this informative speech. Even the professor said to time up ourselves when we rehearse. It's a pity because the topic was so interesting.

As illustrated in Table 2, the students' comments revolved around five main distinguished aspects: Content, non-verbal communication, verbal communication, use of visuals and allotted time. According to the feedback posted on the video blog, most students were generous in providing detailed feedback on the speakers' choice of topic, idea development, use of logical organizational pattern, supporting the main ideas using academic sources, establishing credibility, attention grabber, transitions, and so on. Many expressed their interest in their peers' chosen topic and the way they had approached it. Feedback on the students' content of their speeches is of paramount importance to the speakers since it showed them if and to what extent they managed to engage the audience. Making the topic interesting to the audience and involving them throughout the performance is not an easy task to do. Overall, the comments were clear and straightforward, and the students used concepts and technical terms learnt in the classroom. The majority followed the instructor's guidelines and provided complete constructive feedback to their peers, which helped the students learn from their mistakes and improve their public speaking skills.

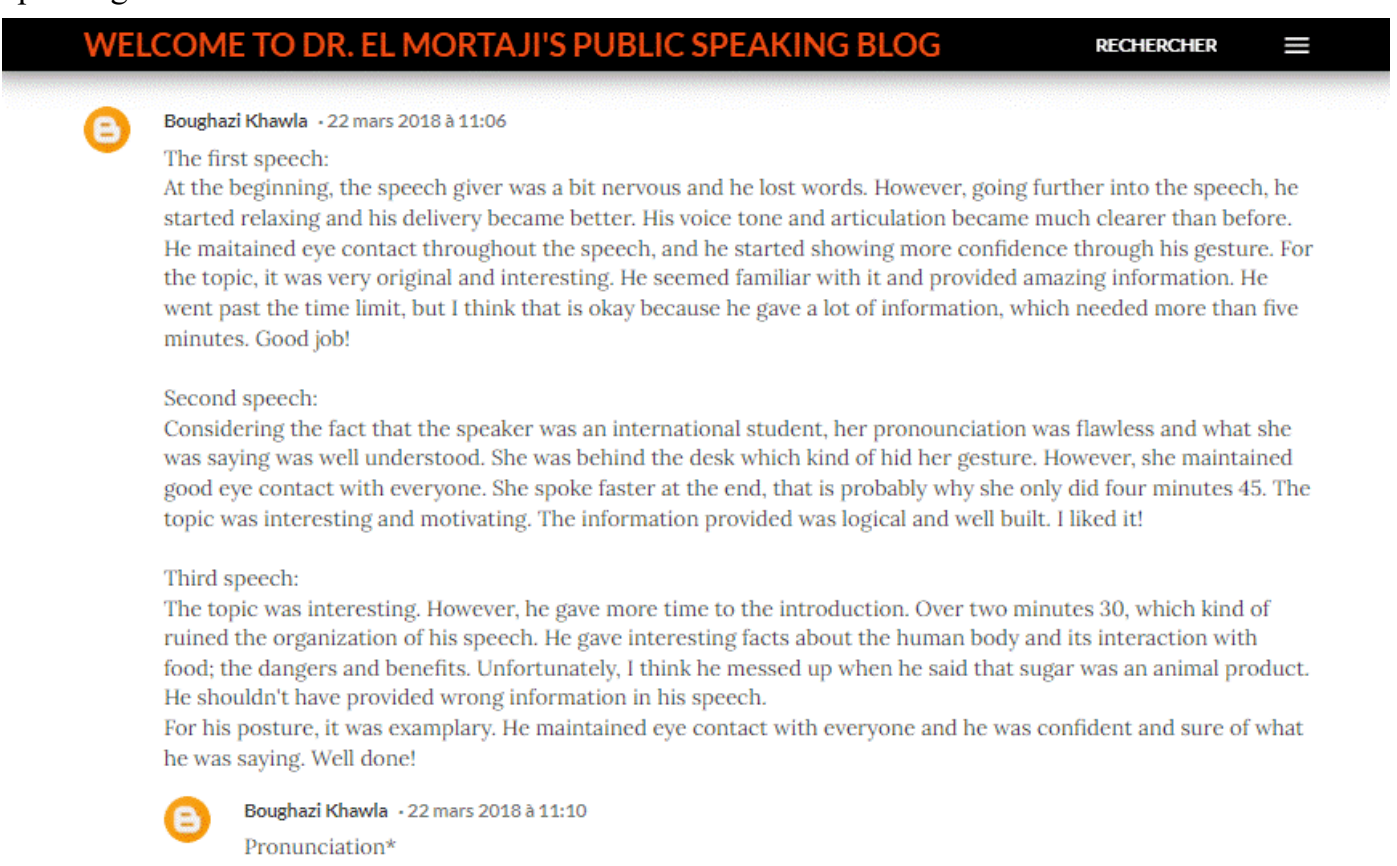

Figure 4. Sample of students' original feedback posted on the blog

Figure 4 is a sample of the authentic and original feedback the students provided on the course blog. In this sample, the female student Khawla provided feedback to three different speakers on their informative speech. She posted her comments on March 22 $2^{\text {nd }}$ at 11:06 am. Her comments pertained to content and delivery: 
-Speech content feedback: original topic, interesting topic, amazing information, motivating topic, logical and well-built information (i.e. ideas), interesting facts, wrong information, summary of the main points, reaction to one of the main ideas.

-Speech delivery: (verbal and non-verbal) feedback: nervous, clearer tone, flawless pronunciation, clear articulation, maintained eye contact, showing more confidence, confident, sure of what he was saying, exemplary posture, was behind the desk which hid her gestures, went past the time, gave more time to the introduction over two minutes thirty seconds which ruined organization of the speech.

-Overall evaluation: Good job! I liked it. Well done!

As demonstrated, the student followed the professor's guidelines provided in the classroom about effective feedback and posted comments pertaining to each aspect of the speech. This is a good example of complete, constructive, and effective feedback. It reflects excellent collaborative learning whereby the student Khawla interacted with her peers successfully and gave them serious and helpful feedback that should enable them to see their strengths and weaknesses in terms of speech preparation and delivery.
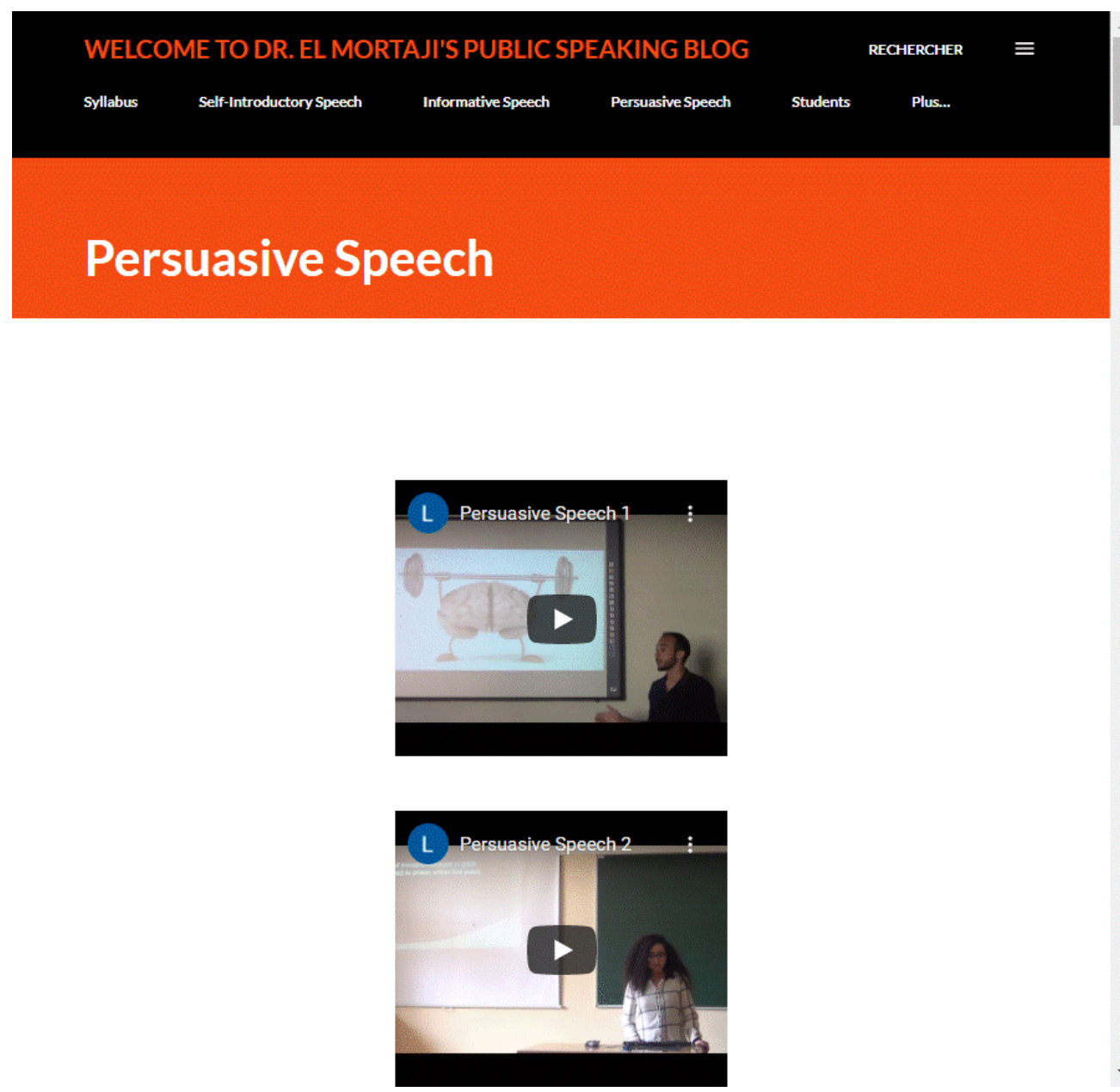

Figure 5. Sample of students' persuasive speech with visuals posted on the blog

In addition to content, verbal and non-verbal communication, the students evaluated the speakers' performance in terms of use of visuals and allotted time. All the speeches involved in this study were timed speeches, and the students were instructed never to go beyond allotted time and to try their best to be as close as possible to the set timing. So, as expected, peer feedback included a few comments about the students' use and abuse of allotted time. While making these comments, some students referred to the techniques the instructor had taught them in class to use in order to achieve the required allotted time, including 'speech rate', 'using a conversational style', 'sticking to the required number of main points', 'not exceeding a specific number of outside sources', 'ignoring details', and 'practicing (rehearsing) with a timer before final delivery'. As for the visuals, they were strictly required in the persuasive speech. Some students reported their satisfaction with 'appropriate and selective use of visuals', that 'added credibility to the speech', and 'helped make the speaker's message understandable'. 


\subsection{Observing Netiquette}

Before the first online interaction, the professor felt the need to repeatedly refer to the list of "netiquette guidelines" as a kind reminder to ensure the students abide by the rules and provide constructive feedback with respect and courtesy toward their peers in their online interaction.

\section{WELCOME TO DR. EL MORTAJI'S PUBLIC SPEAKING BLOG}

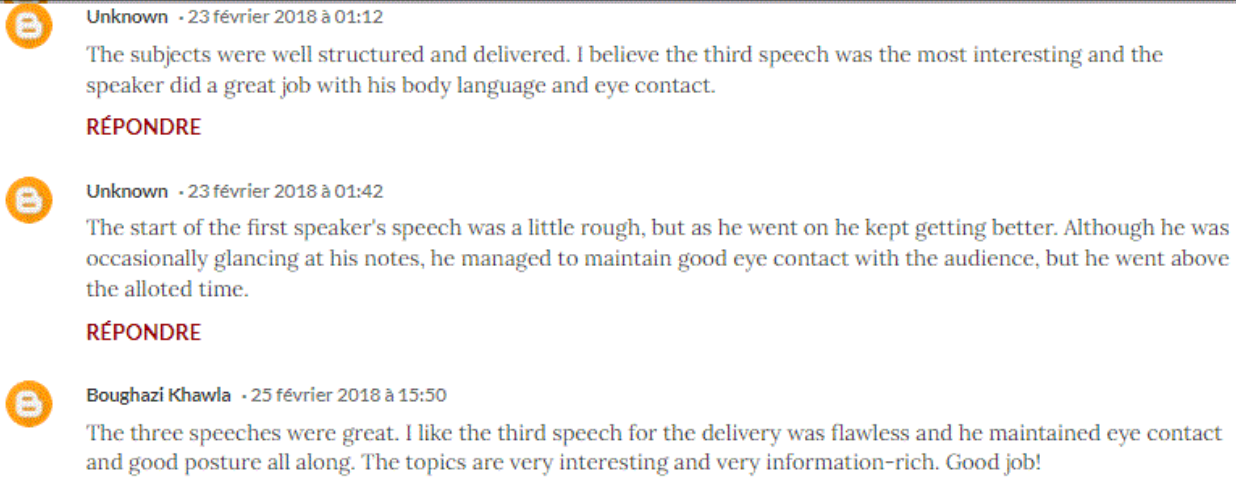

Figure 6. Sample of netiquette in providing feedback on the blog

In this excerpt, three students entered their names and provided brief feedback, which is quite short compared to the sample provided in Figure 4. There were two further comments by two "unknown students" at the bottom of the Figure that were deleted (i.e., it is written in French 'supprimé') because the student did not respect the rules of netiquette that were clearly explained in the classroom. The instructor made sure that all anonymous comments get deleted, and those anonymous authors rewrite their comments making sure their complete name was clearly printed. Failure to do so resulted in receiving a low grade on the online interaction because the instructor had agreed with her students that $10 \%$ of the overall grade would be devoted to online interaction, with the purpose of motivating the students to take their online learning and contribution quite seriously.

\subsection{Turnitin}

All the participants submitted a formal outline for every speech to Turnitin.com. This step was mandatory before uploading the speech to the course blog. Without an outline, the students could not possibly receive a grade for their speech. The screenshot below shows that all students did commit and submitted their work as required. The purpose of this step is to ensure that the students' work is original and not plagiarized. Figure 7 shows the overall Turnitin originality report of all the students' submissions for one specific assignment, while Figure 8 is an example of all the submissions made by one student over the course of the semester.

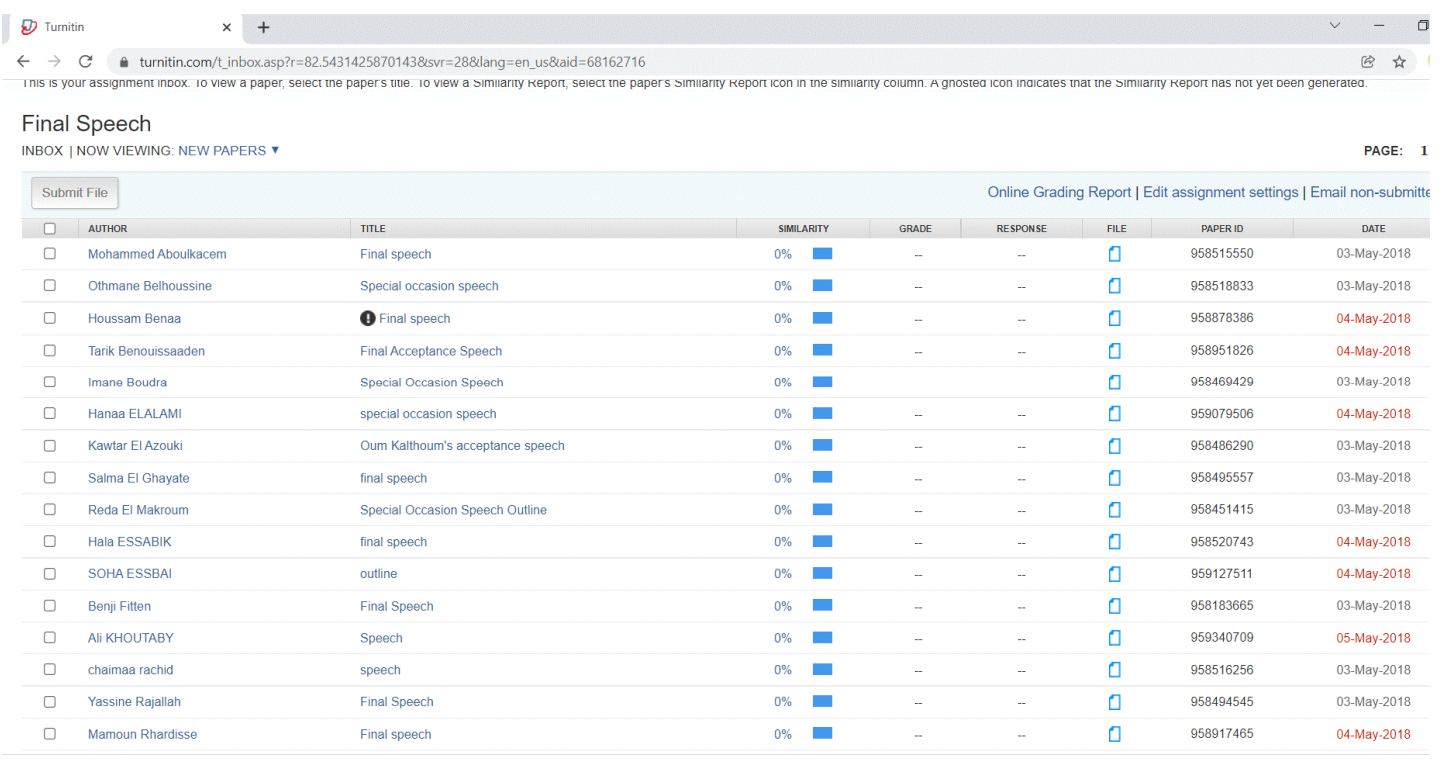

Figure 7 . Turnitin overall originality report 


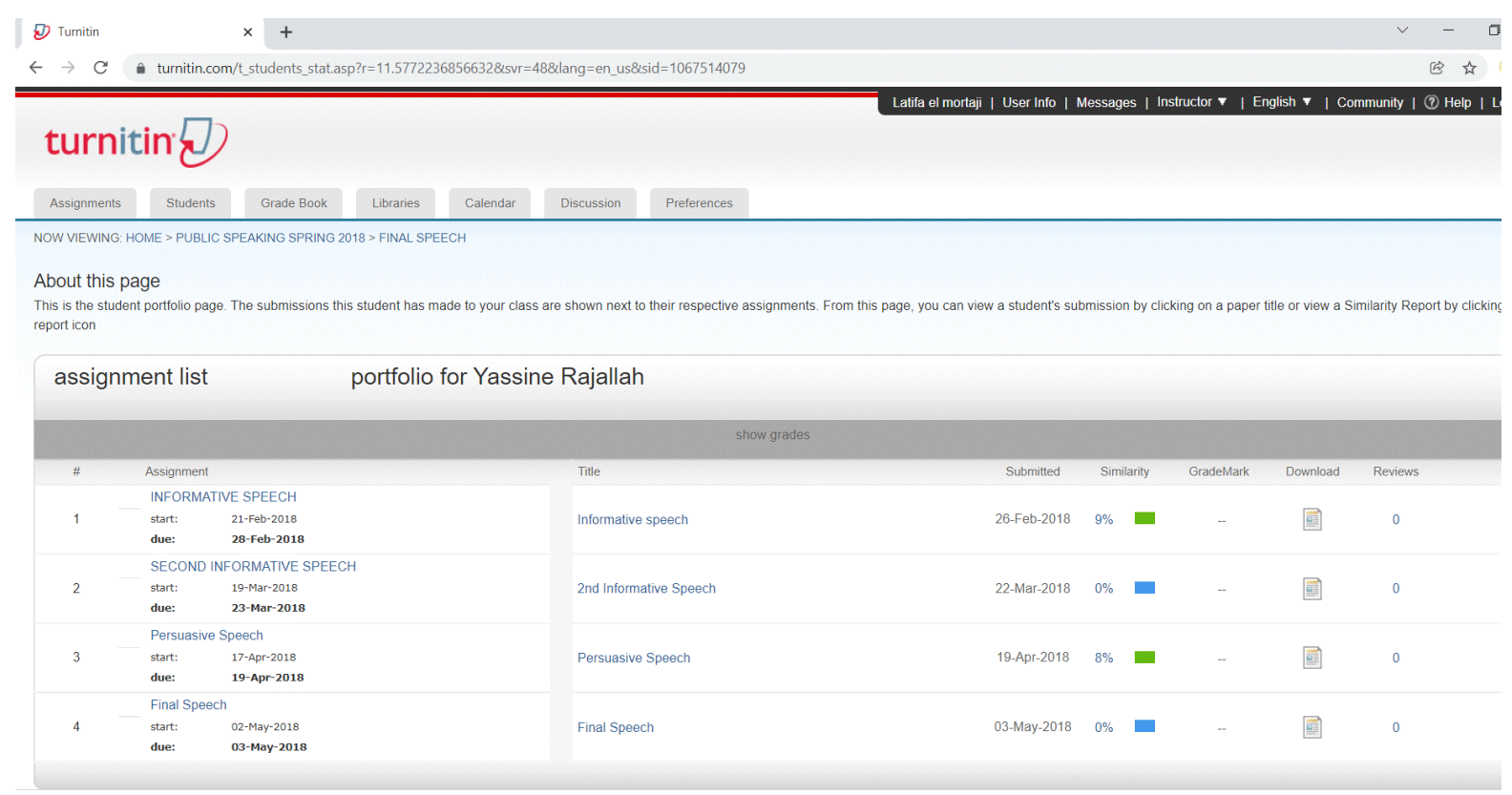

Figure 8. Turnitin portfolio for each individual student

As observed, the students had a regular active presence online on a weekly basis to the course video-based Blog to upload their speech or provide and read received feedback. The instructor could easily see the dates and number of feedbacks provided by each student, together with their uploaded speeches. The instructor checked the blog every week to watch and evaluate the speeches, to check the quality of peer feedback, and observe students' public speaking skills development as the students moved from one speech to another. In addition to the course blog, the students had to use LMS to access guidelines, speech assignments, and other teaching material, but unlike the blog, the professor could not possibly monitor the portal or assess the students' online presence (i.e., frequency). Turnitin also kept a record of the students' work in terms of originality and submission or no submission. The students had to respect the due dates because the system would not accept work after 11:59 pm.

Therefore, the students' online presence and performance was measured by the frequency and quality of their submissions (i.e., speech, outline, peer feedback) to the course blog and Turnitin within the allotted date and time. As stated above, given that the students were familiar with LMS and Turnitin, and the instructor had coached them to video-record and upload their speeches and provide feedback, the instructor did not expect any problematic issues with technology.

\subsection{The Public Speaking Blended Learning Survey}

RQ2. How do students perceive blended learning as a teaching model in their public speaking course?

The participants completed a survey at the end of the semester with a view to providing their views about different parts and aspects of the course, their attitudes towards the technology used, and the overall learning environment.

\subsubsection{Students' Perceptions of Blended Learning}

\section{What do you think of the public speaking blended learning course model?}

All the participants (100\%) enjoyed the public speaking blended learning model for they found it 'well balanced' and 'very interactive'. Most students (95\%) particularly liked the course because it enabled them to have their 'desired face-to-face communication' with the professor, and other sessions outside the classroom whereby they could 'interact with peers online' to provide feedback on posted speech videos. On the other hand, a few students (5\%) reported their 'reservation' about posting their own speeches online. They explained that although the video-tape blog is a 'very interesting platform', quite 'useful', and 'helpful' to them to enhance their learning and 'improve' their public speaking skills, they would rather post their 'selected speeches' and not all of them. They explained that they felt more confident and pleased to share 'good and successful speeches only', in order to receive 'positive feedback'. They felt 'insecure', even 'intimidated', to share a low performance speech for they could not handle receiving negative feedback. Overall, the students found the blended learning model very helpful, useful (95\%), complementary (89\%), and interactive (95\%). It enabled them to have an autonomous and 
collaborative learning. It allowed them to correct their own mistakes and to learn from others. Finally, the students praised online etiquette 'netiquette' observed by their peers using appropriate language when posting comments, probably because the platform was officially academic, and the instructor was observing (controlling) the video-based blog on a weekly basis.

\section{Which part in the blended learning course do you suggest to the teacher to keep or change?}

All the students said the course was well designed and well balanced. They found the traditional face-to-face interaction 'perfect' as it is, and they particularly liked the fact that the professor created one course blog for the three sections, because this way they had to get used to the idea of sharing their 'speech performance with a larger audience' than they were used to, and therefore receive multiple feedback. So, the weekly classroom interaction was a must they said should not be changed.

However, some students suggested that maybe the professor could initially consider using a separate blog for each class section, and this way 'limit the audience size' at the beginning of the semester. Then, when the students acquire some skills after a few speeches, the professor could progressively introduce the speeches to a larger audience (i.e. students across all three sections). By speech three, they explained, the students would have learned from past mistakes and would have gained some experience and developed some public speaking skills. Only then, these students would feel more confident about delivering a successful speech and would welcome feedback from a large audience, including people they do not know.

\subsubsection{Students' Perceptions of Face-to-Face Interaction}

\section{What did you like most/less about the face-to-face interaction?}

All participants $(100 \%)$ reported they enjoyed the course material covered in the classroom. They particularly emphasized that they equally liked the lectures and chapter presentations, followed by impromptu speaking and the in-class speech analysis activities. Impromptu speaking sessions progressively prepared them to become more confident and helped them develop classroom connectedness with their peers. The in-class speech analysis activities introduced them to the online platform both psychologically and technically, since through speech analysis they learned how to provide and accept constructive feedback. Some students praised the face-to-face instruction for it 'fosters social interaction' and 'global communication' $(95 \%)$ among all the students and between the students and the instructor. Students saw the classroom interaction as the 'fundamental part of the course' $(100 \%)$ since they received all the most important materials in class, while the online interaction is complementary (96\%). The traditional instruction in class was considered 'more fun and more positive' (98\%), and it emphasized eye contact, class bonding, body language, posture, and facial expressions. All the students 'could not visualize the course without the in-class interaction' with the instructor $(100 \%)$. Many students 'praised and saluted' the fact that the 'lectures were delivered in class and not online', because the face-to-face interaction with the instructor enabled them to 'ask questions' when they could not understand parts of the lectures or 'when they had difficulties understanding' (95\%) the specific requirements for each academic speech assignment.

In addition, all the students praised the face-to-face rehearsals in the auditorium and found them 'motivational' $(100 \%)$, 'fun activities' $(100 \%)$, and 'empowering' $(100 \%)$. Here is what one specific student said in this respect: "Working together collaboratively on stage to prepare and deliver impromptus has helped us engage with each other and grow as students and individuals. We have learnt to share, to accept the self and the other and build trust. I personally feel becoming more confident, creative and powerful."

As for the second part of the question about which part of the face-to-face interaction they liked less, the answer was 'none'. Thus, the researcher concluded that the students without exception were $100 \%$ fully satisfied with the traditional student-professor interaction in the classroom.

\subsubsection{Students' Perceptions of the Online Interaction}

\section{Which part of the online interaction did you like most/less?}

They reported they 'enjoyed' watching themselves and their peers delivering their speeches. The experience enabled them to perform in an academic environment. The blog made their 'learning easier'. Thanks to the peer-feedback they could reflect on and assess their public speaking skills, and their overall learning experience. Some of the advantages they cited was 'flexibility' in terms of 'time management' since they could access the blog anytime they wanted to watch speeches and provide feedback. Most students, however, saw the 'online learning a complementary part of the class interaction'. 
Disadvantages were mainly 'technical'; for example, when the 'connection was down on campus' in the evening or during the weekend, they 'could not possibly meet online and they 'could not post comments on blog videos'. This 'dissatisfaction' was particularly web-based because of technological fails. Unlike some previous studies, the participants involved in the study were computer literate, they had no difficulties using the discussion board in the portal, the blog, Turnitin or LMS in general. They were competent technology users, and they learned in the classroom how to use the camera to record and upload their speeches.

A few students reported they 'preferred face-to-face to online interaction' because it was 'easier to communicate in class', and 'the instructor's presence in the classroom helped them to 'take their work more seriously' and to 'commit' and 'assume their responsibility as speaker and peer reviewer'. They saw their professor as their mentor who made them feel 'confident', and 'secure', because the instructor guided them throughout their learning in the classroom, and therefore represented a source of 'trust'.

\section{Discussion}

The study revealed the students' great appreciation for the public speaking blended learning mode. They praised both the face-to-face sessions with the instructor and the online student interaction. They found both parts of the blended learning environment effective and complementary. They highly valued the online peer review using the course-video based blog. Thanks to peer feedback they learned from their mistakes; watching the performance of their peers helped them compare their delivery to other peers and set new goals, which turned out to be an effective strategy to correct mistakes and progressively improve their delivery (El Mortaji, 2018). In fact, they improved their public speaking skills as they moved from one speech to another. According to the instructor's evaluation, most students $(90 \%)$ improved their posture, eye contact, hand gestures, voice, and tone. In addition to delivery skills, the students' language skills improved too. This confirms previous findings about female students' confidence and language proficiency skills, including grammar, pronunciation, and articulation which improved significantly (Al-Madani, 2011; AlKhaleel, 2019). In addition, the majority (95\%) of students reported they had learned the importance and value of producing a structured and well-organized sentence outline prior to their speech delivery.

This study revealed that all students were involved in successful online interactions. They were excited and motivated to interact online with their peers, to upload their speeches and provide peer feedback. The same finding regarding effective online feedback was reported in previous BL studies (Shih, 2010). Even those few students who were reluctant at the beginning of the study to share their speech online and receive their peers' feedback, progressively changed their attitudes and had a regular presence online. Similar findings were reported in previous studies (Ibrahim \& Yusoff, 2013). It is worth mentioning here that the constant reminders and guidance the professor provided in the classroom were very much useful to achieve this result. In addition, the professor assigned a grade for providing complete effective constructive feedback to encourage the students and motivate them to interact with each other online. Access to the blog was not monitored, but considering the number and quality of feedback produced on a weekly basis, all students were quite active and interacted as required.

The way the course was designed created a positive balance through more hours in face 2 face than online, which were eventually reduced after the midterm when students got used to take their learning in their hand. Most students learned how to become independent learners and assume their responsibility outside the classroom to take care of their learning by monitoring their progress and improvement online. On the other hand, some students refused to assume such responsibility and rather requested the instructor's guidance throughout; such students used the weekly office hours fully to ensure they were on the right track. Attachment to in-class instruction and to the teacher for many reasons, including "more social interaction and communication" (Marriot and Selwyn, 2004; Osgerby, 2013) "complimenting, using humor, maintaining eye contact and developing good facial expressions and gestures" (Kintu, 2017), could also be cultural because the students in the current study used words like "feeling more secure", "trust", and "liked her welcoming smile" in reference to the instructor.

Practicing with their outline enabled the students to move away from memorizing an entire speech to focusing on and remembering the main points only, which contributed a great deal to using a natural extemporaneous speech delivery that involved using spontaneous word choice, and, therefore, employing different vocabulary and sentence structures. Planning ahead of time and structuring their speech logically were very helpful to the students in the sense that the speech comes naturally, and ideas are expressed freely and easily, which made their speech lively and more engaging. As they changed the bad habit of memorizing their speech, students also realized the importance of developing a short outline prior to their speech delivery. The Turnitin platform provided the students with the tool of resubmission by overwrite that enabled the students to submit multi-drafts 
of their outline and receive their personalized feedback and originality reports before final submission. This activity enabled them to grow as speakers, as they learned to put emphasis on main ideas and not on words.

The study demonstrated that integrating technology in the students' learning is very helpful and effective in online communication and interaction between the students, and it enables them to achieve their tasks in a timely manner, which goes in line with previous studies reporting that computer assisted language learning (CALL) is "comfortable for interaction", contributes to "cooperative learning" (Ranlli, 2008), and enables students to "develop their cognitive and social skills" (Hourigan \& Murray, 2010). Overall, the participants had no technical or technology-related issues, because prior to the study they were all computer literate, they were using the institution's official LMS, and were used to uploading their work, accessing teaching materials, and submitting their outline to Turnitin.com.

However, the main challenge was the connection. Sometimes it was too slow, and there were a few times when they got completely disconnected and could not possibly upload their speech on the blog or provide peer feedback as required. Today, the connection is still an issue for all of us, and hopefully soon the institution will take serious big measures to fix this problem. As for their perceptions of the online platforms, the students found them useful, helpful, flexible (Hyo-Jeong So \& Curtis J. Bonk, 2010), and collaborative, mainly because the basics were covered in class, and materials posted in LMS were mostly of supplementary nature.

Therefore, judging by (i) the overall course learning outcomes' attainment ( $85 \%$ of students earned $>\mathrm{B}+$ ), (ii) the overall success of using the various web-based tools, namely the LMS, Turnitin, the Blog, the recording and posting of videos albeit minor dissatisfaction about connection issues, and contrary to the apprehensions highlighted by Vaddale et al. for the use of somehow new Virtual Reality (VR) technology (Vaddale et al., 2021) in Public Speaking, the use of web-based technology in a blended way for Public Speaking did not seem to bring about any apparent students' technology-related anxiety. This can be explained by the fact that web-based and video technologies are becoming readily used by learners very early in their high school itineraries even before joining University, and that with the advancement of User Experience Design (UXD or UED) (Christensen et al., 2020) in web-based applications that are very much user-centered and which make interaction with web applications intuitive, the Perceived Ease of Use (Davis, 1989) is no longer a determining factor for web-based technology acceptance. Although no attempt was made to measure the Perceived Usefulness (PU) at any time of the course, we believe judging by the level of engagement of the students that whatever it was at the onset of the class, it quickly was apparent that PU was very high.

\section{Conclusion}

In this study, the researcher developed a blended learning course design and progressively implemented it in her public speaking class. This course is very important for it is a common core and introduces the necessary skills for effective communication and presentation in other courses across the students' academic career. The researcher developed the blended learning course because the university has been encouraging online courses' development and implementation. Lately, a few online courses such as professional communication have been offered online, and the institution is in favor of e-learning and is, therefore, moving towards offering distance learning to students. The challenge in the public speaking course is that the students usually get both theory and practice in the classroom, then they independently work on their own speech development with the guidance and support of the professor, while in the BL course they need to become independent learners and rely less on the professor, by partially covering theory and practice themselves, since the professor made all needed materials accessible and available through different platforms, including LMS, a video-based blog, and Turnitin. The study corroborates the statement that as web-based technology is becoming more and more user-centered, its PEU is likely to be a minor parameter for acceptance in today's web-based learning. As such, the researcher encourages the use of such technology in learning.

It also revealed that the Blended Learning mode is effective and has many advantages. Indeed, the results of the study showed that for a public speaking blended learning course model to be implemented effectively, some major factors should be taken into consideration: Teaching experience, effective planning, adequate and interesting resources and teaching material, motivation, online platforms (LMS, Blog, Turnitin), devices (camera, laptop, phone), and an excellent connection. And to ensure successful learning, students' motivation and commitment determine their active presence and performance online to engage in collaborative work and learn together with their peers the technologies and tools (recording, applications) used, and group activities (peer review, collaborative impromptu speech) to enhance their knowledge and improve their public speaking skills. Initially, it is recommended to hold a few face-to-face, physical, or synchronous, sessions to enable the students to understand the nature of the course and its objectives, and to get to know the teacher. 
Considering the students' successful learning achieved through public speaking skills and peer revision skills development, as well as their overall positive attitude and perceptions of the public speaking blended learning model, the instructor intends as a next step to move $80 \%$ of the course content and student-student interaction online and devote the remaining $20 \%$ to physical classroom interaction. She shall conduct another survey to assess the students' achievements, and with more satisfactory results she plans to move ahead towards a $100 \%$ online public speaking course implementation that should definitely maintain synchronous activities but to a minimum, in order to ultimately have a new generation of freshmen capable of taking their college learning in their own hands, using all available resources and technology, especially now that COVID-19 crisis has forced higher institutions around the world to switch to fully online teaching.

\section{References}

Ainol, H., \& Zailin, S. (2012). Teaching public speaking in a blended learning environment. International Journal of Social Science and Humanity, 2(6), 573-576.

Akkoyunlu, B., \& Soylu, M. Y. (2008). A Study of Student's Perceptions in a Blended Learning Environment Based on Different Learning Styles. Educational Technology \& Society, 11(1), 183-193. Retrieved from https://pdfs.semanticscholar.org/708e/a13e965a1efeaac8b462e564afaa010d500b.pdf

AlKhaleel, A. (2019). The Advantages of Using Blended Learning in Studying English as a Foreign Language at the University of Tabuk. Modern Journal of Language Teaching Methods (MJLTM), 9(2). Retrieved from https://mjltm.org/article-1-510-en.html

Al-Madani, F. M. (2015). The Effect of Blended Learning Approach on Fifth Grade Students' Academic Achievement in My Beautiful Language Textbook and The Development of Their Verbal Creative Thinking in Saudi Arabia. Journal of International Education Research, 11(4), 253-260. https://doi.org/10.19030/jier.v11i4.9459

Barson, J., \& Debski R. (1996). Calling back CALL: technology in the service of foreign language learning based on creativity, contingency, and goal-oriented activity. In Warschauer M. (Ed.), Telecollaboration in foreign language learning (pp. 49-68). Honolulu: University of Hawaii, Second Language Teaching and Curriculum Center.

Bersin, J. (2004). How Did We Get Here? The History of Blended Learning. In the Blended Learning Book: Best Practices, Proven Methodologies, and Lessons Learned. Wiley.

Brown, R. (2003). Blended Learning. Rich experiences from a rich picture. Training and Development in Australia, 30(3), 14-17.

Charles, D. D., Joel, L. H., \& Patsy, D. M. (2004). Blended Learning. Educause Center for Applied Research, 2004(7). Retrieved from https://www.educause.edu/media/files/library/2004/3/erb0407-pdf

Christensen, S. Y., Dickinson, J., Machac, K., \& Cline, H. (2020). Define UX Design. Intermountain Engineering, Technology and Computing (IETC), 1-5. https://doi.org/10.1109/IETC47856.2020.9249146

Cuesta Medina, L. (2018). Blended learning: Deficits and prospects in higher education. Australasian Journal of Educational Technology, 34(1). https://doi.org/10.14742/ajet.3100

Davis, F. D. (1989). Perceived usefulness, perceived ease of use, and user acceptance of information technology. MIS Quarterly, 13(3), 319-340. https://doi.org/10.2307/249008

Davis, F. D., Bagozzi, R. P., \& Warshaw, P. R. (1989). User acceptance of computer technology: A comparison of two theoretical models. Management Science, 35(8), 903-1028. https://doi.org/10.1287/mnsc.35.8.982

El Moratji, L. (2017). Effects of sustained impromptu speaking on public speaking anxiety reduction. Journal of Emerging Trends in Educational Research and Policy Studies, 8(4), 216-222. Scholarlink Research Institute. Retrieved from https://journals.co.za/content/journal/10520/EJC-b398ea808

El Mortaji, L. (2018). Effects of sustained impromptu speaking ang goal setting on public speaking competency development: A Case study of EFL college students in Morocco. English Language Teaching, 11(2). https://doi.org/10.5539/elt.v11n2p82

Finn, A., \& Bucceri, M. (2004). A case study approach to blended learning. Retrieved from https://www.centra.com/download/whitepapers/CaseStudy_BlendedLearning.pdf

Friesen, M. (2012). Report: Defining Blended Learning. Retrieved from https://blogs.ubc.ca/nfriesen/2012/09/01/where-does-blended-end- virtual-begin/ 
Garrison, D. R., \& Vaughan, N. D. (2007). Blended learning in higher education: Framework, principles, and guidelines. https://doi.org/10.1002/9781118269558

Graham, C. R. (2006). Blended Learning Systems: Definition, Current Trends, and Future Directions. In Curtis J. Bonk \& Charles R. Graham (Eds.), The Handbook of Blended Learning: Global Perspectives, Local Designs (pp. 3-21). San Francisco, Pfeiffer Publishing.

Graham, R., Moskal, P., Norberg, A., \& Sicilia, N. (2018). Blended learning: The new normal and emerging technologies. International Journal of Educational Technology in Higher Education, 15(3). https://doi.org/10.1186/s41239-017-0087-5

Güzer, B., \& Caner, H. (2014). The Past, Present and Future of Blended Learning: An In- Depth Analysis of Literature. Procedia - Social and Behavioral Sciences, 116, 4596-4603. https://doi.org/10.1016/j.sbspro.2014.01.992

Harding, T., \& Whitehead, D. (2016). Analysing data in qualitative research. In Schneider, Z., Whitehead, D., LoBiondo-Wood, G. \& Haber, J. (Eds.), Nursing \& Midwifery Research: Methods and Appraisal for Evidence-Based Practice (5th ed., pp. 128-138). Elsevier - Mosby, Marrickville, Sydney.

Hourigan, T., \& Murray, L. (2010). Using blogs to help language students to develop reflective learning strategies: towards a pedagogical framework. Australian Journal of Educational Technology, 26(2). https://doi.org/10.14742/ajet.1091

Hrastinski, S. (2019). What Do We Mean by Blended Learning? TechTrends, 63, 564-569. https://doi.org/10.1007/s11528-019-00375-5

Hyo-Jeong So, \& Bonk, C. J. (2010). Examining the Roles of Blended Learning Approaches in Computer-Supported Collaborative Learning (CSCL) Environments: A Delphi Study. Educational Technology \& Society, 13(3), 189-200. Retrieved from https://www.jstor.org/stable/jeductechsoci.13.3.18

Ibrahim, A. H., \& Yusoff, Z. S. (2012). Teaching Public Speaking in a Blended Learning Environment. International Journal of Social Science and Humanity, 2(6), 573-576. https://doi.org/10.7763/ijssh.2012.V2.175

Kintu, M. J., \& Zhu, C. (2016). Student characteristics and learning outcomes in a blended learning environment intervention in a Ugandan University. Electronic Journal of e-Learning, 14(3), 181-195.

Kintu, M. J., Zhu, C., \& Kagambe, E. (2017). Blended learning effectiveness: the relationship between student characteristics, design features and outcomes. International Journal of Educational Technology in Higher Education, 14. https://doi.org/10.1186/s41239-017-0043-4

Martyn, M. (2003). The Hybrid online model: Good practice. Educause Quarterly, (1), 18-23. Retrieved from https://er.educause.edu/-/media/files/article-downloads/eqm0313.pdf

Morse, J. M., \& Richards, L. (2002). Readme First for a User's Guide to Qualitative Methods. Thousand Oaks, London, New Delhi: Sage.

Pappas, C. (2019). The History of Blended Learning. Retrieved from https://elearningindustry.com/history-of-blended-learning

Qindah, S. (2018). The Effects of Blended Learning on EFL Students' Usage of Grammar in Context. The Eurasia Proceedings of Educational \& Social Sciences (EPESS), 10, 11-22. Retrieved from https://dergipark.org.tr/en/download/article-file/534204

Ranalli, J. (2008). Learning English with The Sims: Exploiting authentic computer simulation games for L2 learning. Computer Assisted Language Learning, 21(5), 441-455. https://doi.org/10.1080/09588220802447859

Rao, V. C. S. (2019). Blended Learning: A New Hybrid Teaching Methodology. Journal for Research Scholars and Professionals of English Language Teaching, 13(3), 1-6. Retrieved from https://www.researchgate.net/publication/333485907_Blended_Learning_A_New_Hybrid_Teaching_Meth odology

Ross, B., \& Gage, K. (2006). Global perspectives o blended learning: Insight from WebCT and our customers in higher education. In C. J. Bonk \& C. R. (Eds.), Handbook of blended learning: Global perspectives, local designs (pp. 155-168). San Francisco: Pfeiffer. 
Shih, R. C. (2010). Blended learning using video-based blogs: Public speaking for English as a second language students. Australasian Journal of Educational Technology, 26(6), 883-897. https://doi.org/10.14742/ajet.1048

Staker, H., \& Horn, M. B. (2012). Classifying K-12 Blended Learning. Distributed by ERIC Clearinghouse. Retrieved from https://www.christenseninstitute.org/wp-content/uploads/2013/04/Classifying-K-12-blended-learning.pdf

Vallade, J. I., Kaufmann, R., Frisby, B. N., \& Martin, J. C. (2021). Technology acceptance model: investigating students' intentions toward adoption of immersive $360^{\circ}$ videos for public speaking rehearsals. Communication Education, 70(2), 127-145. https://doi.org/10.1080/03634523.2020.1791351

Walker, Z., Kho, H. H., Tan, D., \& Lim, N. (2019). Practicum teachers' use of mobile technology as measured by the technology acceptance model. Asia Pacific Journal of Education, 40(2), 230-246. https://doi.org/10.1080/02188791.2019.1671808

Watson, J. (2008). Blending Learning: The Convergence of Online and Face-to-Face Education. NACOL. Retrieved from https://files.eric.ed.gov/fulltext/ED509636.pdf

Westerlaken, M., Christiaans-Dingelhoff, I., Filius, R. M. et al. (2019). Blended learning for postgraduates; an interactive experience. BMC Medical Education, 19. https://doi.org/10.1186/s12909-019-1717-5

Yeh, H. C., Tseng, S., \& Chen, Y. (2019). Using Online Peer Feedback through Blogs to Promote Speaking Performance. Educational Technology \& Society, 22(1), 1-14. Retrieved from https://www.jstor.org/stable/26558824

\section{Copyrights}

Copyright for this article is retained by the author(s), with first publication rights granted to the journal.

This is an open-access article distributed under the terms and conditions of the Creative Commons Attribution license (http://creativecommons.org/licenses/by/4.0/). 